\title{
Investigating the Moderating Effects of Size of MNCs in the Relationship between Relationship Characteristics and Degree of Inter-Firm Technology Transfer
}

\author{
Sazali Abdul Wahab \\ National Defence University of Malaysia, Kuala Lumpur, 57000, Malaysia \\ E-mail: saw@upnm.edu.my \\ Raduan Che Rose \\ National Defence University of Malaysia, Kuala Lumpur, 57000, Malaysia \\ E-mail: raduan@upnm.edu.my \\ Suzana Idayu Wati Osman \\ Felda Global Ventures Holdings, Kuala Lumpur, 54000, Malaysia \\ E-mail: suzana.iwo@gmail.com
}

Received: October 22, 2010

Accepted: July 4, 2011

doi:10.5539/jsd.v4n4p190

\begin{abstract}
Based on the underlying knowledge-based view (KBV) and organizational learning (OL) perspectives, the main objective of this paper is to empirically examine the moderating effect of size of MNCs on the relationships between relationship characteristics: relationship quality and mutual trust and two distinct dimensions of degrees of technology transfer: degrees of tacit and explicit knowledge within IJVs. Using the moderated multiple regression (MMR), the theoretical models and hypotheses in this study were tested based on empirical data gathered from 128 joint venture companies registered with the Registrar of Companies of Malaysia (ROC). The results revealed that size of MNCs has significantly affected the relationship between relationship characteristics (relationship quality and mutual trust) and degree of tacit knowledge; where the relationship was found stronger for medium/small MNCs than large MNCs. However, size of MNCs did not moderate the relationship between relationship characteristics and degree of explicit knowledge. The study has bridged the literature gaps in such that it offers empirical evidence on the moderating effect of size of MNCs on the relationships between relationship characteristics and two distinct degrees of technology transfer: degrees of tacit and explicit knowledge using the Malaysian sample.
\end{abstract}

Keywords: Degree of Inter-Firm Technology Transfer, International Joint Ventures, Size of Multinationals, Malaysia

\section{Introduction}

While technology transfers through international joint ventures (IJVs) have been acknowledged by many studies as the most efficient formal mechanism in internalizing the partner's technologies, knowledge and skills, the transfer process has frequently involved various facilitators, actors and complex relationship between partners which cause direct impact on degree of technology transfer. Since the current issue on inter-firm technology transfer (TT) in the developing countries is centered on the efficiency and effectiveness of the transfer process by the multinationals (MNCs) therefore the success is often associated with degree of technology transferred to local partners. Previous studies on intra-firm knowledge transfer have confirmed the significant influence of technology actors and facilitators (barriers) such as the characteristics of knowledge transferred, source, recipient and contextual/relational on knowledge transfer process (Szulanski, 1996, 2000, 2003; Gupta and Govindarajan, 2000; Minbaeva, 2007). In the context of inter-firm TT where technology transfer processes involve more complex relationship, the impending issue now is on the effects of relationship characteristics (RCHAR) on degree or level of technology transfer (TTDEG).

The current issue of technology transfer in the developing countries is centered on the effectiveness, efficiency and successful implementation of technology transfer process (Narayanan and Lai, 2000; Lai and Narayanan, 1997), where the success has frequently been associated with degree of technologies that are transferred to local firms (Pak and Park, 2004; Yin and Bao, 2006). This is mainly because the technology transfer success is not merely possessing the ability to operate, maintain or repair machineries at the production level (transmission) but it also includes the ability to successfully learn, acquire, adopt and apply new external technologies and knowledge (absorption) (Davenport and Prusak, 1998, 2000). Technology transfer initiatives should not only act 
as a catalyst for national economic growth but more importantly as a perfect mechanism to increase local organizations' performance, competitiveness, technological and innovation capabilities, and productivity.

In their efforts to materialize these noble objectives, organizations in the developing countries are seriously attempting not only to eliminate the inter-firm technology transfer barriers and reduce technological gaps that inhibit a higher transfer of advance technologies; which are attributed to knowledge, recipient, supplier and relationship characteristics, but they are also trying to assess and estimate the extent of significant effect of these critical determinants of technology transfer on degree of technology transfer. Moreover, organizations in the developing countries are very concerned about the significant role played by tacit and explicit knowledge in strengthening both corporate and human resource performances. Realizing that both tacit and explicit technologies are the main source of competitive advantage of foreign MNCs therefore in order to increase and further improve their organizational performance, the local organizations are facing a major challenge to fully optimize and extract the potential benefits/opportunities of learning both tacit and explicit knowledge that arise from IJVs.

The relationship (relational) characteristics have increasingly become dominant factors in determining the success or failure of inter-firm technology transfer within IJVs (Pak and Park, 2004; Minbaeva, 2007). Based on literature review, a large stream of literatures has identified the relationship characteristic (RCHAR); which include JV's characteristics, as organizational distance (Simonin, 1999a, 1999b), cultural distance (Lyles and Salk, 1996; Mowery et al., 1996; Choi and Lee, 1997; Inkpen, 1998a, 1998b, Liu and Vince, 1999), organizational context (Kogut and Zander, 1993; Zander and Kogut, 1995), knowledge connection (Inkpen, 2000), organizational structure (Inkpen, 1997), ownership type (Kogut, 1988; Mowery et al., 1996), ownership equity (Pak and Park, 2004), relationship openness (Hamel, 1991; Inkpen, 2000), partners attachment (Inkpen and Beamish, 1997), inter-partner trust (Baughn et al., 1997; Morrison and Mezentseff, 1997; Love and Gunasekaran, 1999, Inkpen, 2000), empathy (Buckley et al., 2002), relationship quality and strength (Szulanski, 1996; Lin, 2005), relational openness (Wathne et al., 1996), relational capital (Kale et al., 2000), informal relationship (Clarke et al., 1998), articulated goals and management commitment (Choi and Lee, 1997; Morrison and Mezentseff, 1997), and legal, political and technical differences (Marcotte and Niosi, 2000).

Although many studies have acknowledged the significant effect of knowledge transfer determinants on knowledge transfer outcomes, nevertheless, the effects of RCHAR on TTDEG in inter-firm TT could possibly have been moderated by other established factors such as size of MNCs (MNCSIZE), age of JV, MNCs' country of origin, and MNCs' types of industry. In other words the variations in TTDEG could have been significantly influenced or moderated by these variables. Bulk of studies on knowledge transfer and acquisition in strategic alliance (Szulanski, 1996; Gupta and Govindarajan, 2000; Minbaeva, 2007; Pak and Park, 2004; Lin, 2005; Wang and Nicholas, 2005; Liao and Hu, 2007; Bresman et al., 1999; Mowery et al., 1996; Lyles and Salk, 1996; Kogut and Zander, 1993; Grosse, 1996: Dhanaraj et al., 2004; Hau and Evangelista, 2007) have not tested the impact (strength) of moderating variables on the linear (direct) relationships between relationship characteristics and technology or knowledge transfer. Nevertheless, a number of studies on inter-firm KT and knowledge acquisition in strategic alliance and JVs have acknowledged the important role of moderating variables such as: 1) collaborative know-how, learning capacity and alliance duration (Simonin, 1999a), 2) collaborative experience and firm size (Simonin, 1999b), 3) organizational culture, firm size, alliance form, and competitive regime (Simonin, 2004), 4) age of JV (Mohr and Sengupta, 2002), 5) alliance origin and alliance experience (Yin and Bao, 2006), 6) age of JV (Tsang et al., 2004), and 7) environmental challenge (Hau and Evangelista, 2007). Following the recent approach in the strategic alliance literature (Simonin, 1999a, 1999b, 2004; Yin and Bao, 2006; Tsang et al., 2004) and based on the underlying knowledge-based view (KBV) and organizational learning (OL) perspectives, this study fills in the literature gaps by specifically examining the effect of size of MNCs (large vs. medium/small MNCs) as a moderating variable in the relationships between the RCHAR and two distinct dimensions of degree of technology transfer: degrees of tacit (TCTDEG) and explicit (EXPDEG) knowledge. The primary objective is to provide new insights and information on the boundary conditions for RCHAR-TTDEG relationship (Aguinis, 2004).

\section{Theory and Hypotheses}

The organizational learning (OL) literature suggests that acquiring and transferring technology require frequent and effective interactions between the supplier and recipient as knowledge is firm-specific, embedded in firm organizational context, personal quality in nature and idiosyncrasy (Nonaka, 1994; Kogut and Zander, 1992, 1993; Bresman et al., 1999). Studies have also acknowledged relationship quality (RELQLTY) as the critical element of relationship characteristic in both intra and inter-firm knowledge transfer (Szulanski, 1996; Gupta and Govindarajan, 2000; Lin, 2005; Gupta, 1987; Wang et al., 2004; Bresman et al., 1999). RELQLTY promotes intimacy of relationship between the source and recipient unit (Szulanski, 1996), informality, openness and density of communication (Gupta and Govindarajan, 2000), and increases openness of communication, spontaneous and open exchange of information between interacting parties (Gupta, 1987). In the context of strategic alliance, RELQLTY promotes greater opportunities to learn, share and access alliance partners' 
strategic knowledge and competencies. It also creates higher relationship openness which could directly affect the willingness of alliance partner to share information and communicate openly (Inkpen, 1998a).

Previous studies have suggested that mutual trust (MT) creates opportunities for a mutual inter-organizational learning when partners become more open and committed in sharing their knowledge and competencies, less protective of their knowledge, and develop free exchange of information between partners (Inkpen, 2000). When the level of transparency or openness between the alliance partners is high, the propensity for inter-partner learning is also high as knowledge is more accessible due to free exchange of information (Hamel, 1991; Doz and Hamel, 1998; Inkpen, 2000). MT encourages partners to be more open and transparent in exchanging, sharing, and transferring knowledge and technology between them due to non-existence of opportunistic behaviors (Kale et al., 2000; Gulati, 1995; Uzzi, 1997; Child and Faulkner, 1998; Steensma and Lyles, 2000; Lane et al., 2001). MT is found to have reduced search cost, increased benefits and alliance's performance (Gulati, 1995), increased alliance's cooperation, improved flexibility, reduced the coordinating activities cost, and increased knowledge transfer and learning (Smith et al., 1995). Past studies have affirmed that MNCSIZE has a significant effect on the intensity of strategic partnering and technological cooperation (Hagedoorn and Schakenraad, 1994), propensity of the firm to develop competitive advantage and achieve the above-average performance (Porter, 1980), organizational learning (Marquardt and Reynolds, 1994), motives for alliance formation (Glaister and Buckley, 1996), and asymmetric bargaining power between partners in the alliance relationship (Khanna et al., 1998). Generally, as compared to large firms, small firms do not have adequate resources and expertise to undertake inter-firm TT and are more likely to transfer technology through licensing agreements (Stobaugh, 1998). Empirical studies have found that MNCSIZE has a significant moderating effect on the relationships 1) between experience, know-how and collaborative relationship, and 2) between knowledge tacitness and ambiguity (Simonin, 1997; Simonin, 2004; Dhanaraj et al., 2004; Bresman et al., 1999). However, other studies have found MNCSIZE did not moderate 1) the knowledge-performance relationship, and absorptive capacity, and 2) learning and IJV performance relationship (Tsang et al., 2004; Lane et al., 2001).

H1: The size of MNCs moderates the relationship between relationship characteristics and degree of tacit knowledge in inter-firm technology transfer.

H2: The size of MNCs moderates the relationship between relationship characteristics and degree of explicit knowledge in inter-firm technology transfer.

\section{Methods}

\subsection{Sample}

The sample frame was taken from the IJV companies registered with the Registrar of Companies (ROC). As at $1^{\text {st }}$ January 2008, the number of IJVs operating in Malaysia was 1038. Out of this, 850 IJVs were considered as active IJVs and 103 IJVs were either dormant or had ceased operation. Since the focus of this study is on inter-firm TT from foreign MNCs to local companies, $85 \mathrm{IJVs}$ were further eliminated from the population frame because only IJVs that have operated more than 2 years and have at least twenty percent (20\%) of foreign equity are eligible to participate in the survey. Therefore, based on the list provided by ROC, which is considered as the most official and original source of information on foreign investment in Malaysia, it was decided that all IJVs (850) be included in the survey. Data collection was conducted in the period from July 2008 to December 2008 using a self-administered questionnaire. The questionnaires were mailed to 850 active JV companies as listed with ROC using a cover letter. After one month from the posting date the response was found not encouraging. By mid July 2008 there were only 70 responses received from the respondents. Thus, in order to increase the response rate the researcher followed-up through numerous phone calls, e-mails, reminders via letters and personal visits to seek the respondents' cooperation in the survey. After intensive efforts were made, by mid November 2008 a total of 145 responses $(17.05 \%)$ were received. Based on literature review, the response rates for mailed questionnaires are usually not encouraging and low (Newman, 2003; Sekaran, 2003). In the Malaysian context, however, a response rate of $15 \%$ to $25 \%$ is still being considered appropriate and acceptable (Mohammed, 1998). From 145 responses only 128 questionnaires were usable and 17 questionnaires were returned blank, returned incomplete, or replied but unable to participate in the study.

\subsection{Instrument and Measurement}

The main research instrument in this study is the questionnaire. Building on the previous TT and KT studies, the questionnaire adopts a multi-item scales which have been modified accordingly to suit the context of the study: inter-firm TT. Except for degree of technology transfer (TTDEG), all the variables are measured using ten-point Likert Scale $(1=$ strongly disagree to $10=$ strongly agree $)$. For TTDEG, this variable is measured using ten-point Likert Scale $(1=$ very low transfer to $10=$ substantial transfer $)$. The ten-point Likert Scale was selected because 1) the wider distribution of scores around the mean provides more discriminating power, 2) it is easy to establish covariance between two variables with greater dispersion around their means, 3) it has been well established in academic and industry research, and 4) from a model development perspective, a ten-point scale is more preferred (Allen and Rao, 2000). 


\subsection{Dependent Variable - Degree of Technology Transfer (TTDEG)}

Following Lyles and Salk (1996), Lane et al. (2001), Gupta and Govindarajan (2000), Dhanaraj et al. (2004), Pak and Park (2004), Yin and Boa (2006) and Minbaeva (2007), this study adopts "a multi-dimensional operationalization approach" in measuring this construct. This study operationalizes TTDEG as the transfer of technological knowledge in terms of two dimensions: 1) tacit knowledge (TCTDEG) in terms of new product/service development, managerial systems and practice, process designs and new marketing expertise, and 2) explicit knowledge (EXPDEG) in terms of manufacturing/service techniques/skills, promotion techniques/skills, distribution know-how, and purchasing know-how. The respondents were asked to evaluate TTDEG from MNCs to local firms in terms of tacit and explicit dimensions of technological knowledge. The Cronbach Alphas for TCTDEG and EXPDEG were 0.96 and 0.97 respectively. The results of Cronbach Alpha were quite similar to that of Hau and Evangelista (2007) and Yin and Bao (2006).

\subsection{Independent Variables}

\subsubsection{Relationship Characteristics (RCHAR)}

This study operationalizes RELQLTY in terms of relationship informality, openness and communication density; which increases the exchange of information, technology and knowledge between partners (Gupta, 1987; Gupta and Govindarajan, 2000; Lin, 2005). To capture this construct, this study employs a four (4) items scale developed by Lin (2005) in which the items are designed to capture 1) the local JV partner efforts in maintaining frequent interaction with the foreign JV partner, 2) the adequacy of the interaction, 3) the local JV partner effort in maintaining an amiable climate for the interaction, and 4) the local JV partner's effort in ensuring that interaction is a constructive mode. As RELQLTY (informality, openness and communication density) is explained by the relationship strength, this study adopts a seven (7) items scale adopted from Cavusgil et al. (2003), Chua (2002), and Fryxell et al. (2002). RELQLTY is measured in terms of 1) the desire to maintain a good social relationship by the foreign and local JV partners, 2) the foreign and local JV partners can freely talk to each other about difficulties (in general) they encounter with JV and they know that their concern will be addressed, 3) the foreign and local JV partners are confident in each other's capabilities, 4) the foreign and local JV partners are free to share their ideas, feelings and hope with each other, 5) the foreign and local JV partners are supportive of each other and they respond constructively and caringly to their partner's concern about the JV, 6) the foreign and local JV partners share a sense of togetherness, and 7) the foreign and local JV partners share organizational myths and stories with each other. The Cronbach Alpha for RELQLTY was slightly higher (0.96) than that of Lin (2005).

\subsubsection{Mutual Trust (MT)}

This study employs a six (6) items scale developed by Dhanaraj et al. (2004) and five (5) item scales from Kale et al. (2000) to measure MT between JV partners which include statements whether 1) the JV partners can understand each other well and quickly, 2) the JV partners have the feeling of being mislead, 3) the JV partners make damaging demands, 4) the stronger JV partner pursues its interest at all costs, 5) the informal agreement are perceived as significant as formal agreement, and 6) the JV partners take advantage on the weakness of the other party (Dhanaraj et al., 2004). In addition, five (5) more items are adopted from Kale et al. (2000) with respect to statements whether the JV is characterized by close interaction, mutual respect, mutual trust, personal friendship, and reciprocity between the JV partners at multiple levels. The Cronbach Alpha was lower slightly lower (0.88) than Dhanaraj et al. (2004).

\subsection{Moderating Variable - Size of MNCS (MNCSIZE)}

Following the previous studies (Simonin, 1999a; Tsang et al., 2004; Dhanaraj et al., 2004), MNCSIZE is measured by the total employees of the foreign JV partner based on items coded: $0=$ large MNCs (employees $>$ 1000 ) and $1=$ small/medium MNCs (employees < 1000) (Yin and Bao, 2006).

\subsection{Model and Analysis}

The moderated multiple regression (MMR) analysis is described as an inferential procedure which consists of comparing two different least-squares regression equations (Aguinis, 2004; Aiken and West, 1991; Cohen and Cohen, 1983; Jaccard et al., 1990). Using the MMR analysis, the moderating effect of the variable (product term) was analyzed by interpreting 1) the $R^{2}$ change in the models obtained from the model summaries, and 2) the regressions coefficients for the product term obtained from the coefficients tables. Prior to conducting the MMR analysis, preliminary analyses were conducted to ensure that there was no violation of the assumptions of normality, linearity, homoscedasticity, and homogeneity of error variance. The population data was carefully examined to avoid the occurrence of 1) Type 1 error; which is the error of rejecting the true null hypotheses at a specified $\alpha$, and 2) Type 2 error ( $\beta$ ); which is the error of failing to reject a false null hypotheses at a specified power (Aguinis, 2004). In this study, Equation 1 below was used to represent the variables in the ordinary least-squares (OLS) model:

Equation 1 (OLS model): $\quad \mathrm{Y}=\beta 0+\beta 1 \mathrm{X}+\beta 2 \mathrm{Z}+e$ 
To determine the presence of moderating effect, the OLS model was then compared with the MMR model which was represented by Equation 2 below:

Equation 2 (MMR model): $\quad \mathrm{Y}=\beta 0+\beta 1 \mathrm{X}+\beta 2 \mathrm{Z}+\beta 3 \mathrm{X} * \mathrm{Z}+e$

where, $Y=$ degree of technology of transfer (TCTDEG and EXPDEG as the dependent variables), $X=$ relationship characteristics (relationship quality and mutual trust), $\mathrm{Z}=$ a hypothesized binary grouping moderator (MNCSIZE; large vs. medium/small), $X * Z=$ the product between the predictors (RCHAR*MNCSIZE), $\beta 0=$ the intercept of the line-of-best-of-fit which represents the value of $Y$ when $X=0, \beta 1=$ the least-squares estimate of the population regression coefficient for $X, \beta 2=$ the least-squares estimate of the population regression coefficient for $Z, \beta 3$ = the sample-base least-squares estimates of the population regression coefficient for the product term, and $e=$ the error term. The moderating variable (product term) is a binary grouping moderator; where the moderating variable MNCSIZE was coded using the dummy coding system; $0=$ large MNCs, and $1=$ medium/small MNCs. This was done because of its simplicity and ease of interpretation of results when making comparisons between different groups (Aguinis, 2004).

\section{Results}

Table 1 and Table 2 show the model summary for both degrees of tacit (TCTDEG) and explicit (EXPDEG) knowledge. The coefficients for all variables for Model 1 and Model 2 (for both TCTDEG and EXPDEG) are presented in Table 3 and Table 4. Table 1 shows that for Model $1, R=.543, R^{2}=.295$ and $[F(2,125)=26.126$, $p=.0001]$. This $R^{2}$ means that $29.5 \%$ of the variance in the TCTDEG is explained by RCHAR scores and MNCSIZE. Model 2 shows the results after the product term (RCHAR*MNCSIZE) was included in the equation. Table 1 also indicates that the inclusion of the product term resulted in an $R^{2}$ change of $.073,[F(1,124)$ $=14.334, p<0.001]$. The results support the presence of a moderating effect. To put it differently, the moderating effect of MNCSIZE explains $7.3 \%$ variance in the TCTDEG above and beyond the variance by RCHAR scores and MNCSIZE. Thus, it can reasonably be concluded that hypothesis $H 1$ is supported.

Table 2 shows that for Model $1, R=.594, R^{2}=.353$ and $[F(2,125)=34.032, p=.0001]$. This $R^{2}$ means that $35.3 \%$ of the variance in the EXPDEG is explained by RCHAR scores and MNCSIZE. Model 2 also shows the results after the product term (RCHAR*MNCSIZE) was included in the equation. Table 2 above indicates that the inclusion of the product term resulted in an $R^{2}$ change of $.010,[F(1,124)=1.921, p>0.05]$. The results show no presence of significant moderating effect. To put it differently, the moderating effect of MNCSIZE explains only $1.0 \%$ variance in the EXPDEG above and beyond the variance by RCHAR scores and MNCSIZE. Thus, it can safely be concluded that hypothesis $H 2$ is not supported. The coefficients table for TCTDEG as shown in Table 3 depicts the results of the regressions equation for Model 1 and Model 2. Model 1 indicates that RCHAR was statistically significant $(p<0.001$; Beta value $=.451)$; and MNCSIZE was statistically significant $(p<0.01$; Beta value $=-0.214)$. Equation 3 below shows that for a 1 -point increase in RCHAR, the TCTDEG is predicted to have a difference by .096, given that the MNCSIZE is held constant. The regression coefficient associated with MNCSIZE means that the difference in TCTDEG between large and medium/small MNCs is -2.520 , given that RCHAR is held constant.

Equation 3: TCTDEG $=10.979+.096 \mathrm{RCHAR}-2.520 \mathrm{MNCSIZE}$

The high-order of interaction effects of the MMR test was conducted to differentiate the extent of TCTDEG that was influenced by large and medium/small MNCs. Model 2 shows the results after the product term (RCHAR*MNCSIZE) was included in the equation. As indicated in Table 1 the inclusion of product term resulted in an $R^{2}$ change of $.073,[F(1,124)=14.334, p<0.001]$. Model 2 shows RCHAR was highly significant $(p<0.001$; Beta value $=.761)$. Both MNCSIZE and RCHAR*MNCSIZE were also found to be significant $(p<0.01$; Beta value $=1.300$ and $p<0.0001$; Beta value $=-1.496$ respectively). The results support the presence of a moderating effect. Table 3 also reveals information on the regression coefficients after the inclusion of product term in the equation. The equation for Model 2 is as follows:

Equation 4: TCTDEG $=.719+.163 \mathrm{RCHAR}+15.297 \mathrm{MNCSIZE}-.120 \mathrm{RCHAR} * \mathrm{MNCSIZE}$

As indicated above, the interpretation of the regression coefficients is based on the fact that the binary moderator was coded using the dummy code system. The result for Model 2 indicates that for a 1-point increase in the RCHAR, the TCTDEG is predicted to have a difference by .163, given that MNCSIZE is held constant. The interpretation of the regression coefficients for the product term in Equation 4 is that there was a -.120 difference between the slope of TCTDEG on RCHAR between large and medium/small MNCs. In other words, the slope regressing TCTDEG on RCHAR is steeper for medium/small MNCs as compared to large MNCs. The RCHAR and TCTDEG relationship for large and medium/small MNCs is shown in Figure 1 below by creating a graph displaying the relationships for each of the groups (Aguinis, 2004). From the results of descriptive statistics, the value of the mean score for RCHAR is 6.68; and for the standard deviation $(S D)$ is 1.23. Following Aguinis (2004), the value $1 S D$ above the mean is 7.91 and the value $1 S D$ below the mean is 5.45 . Thus, using the value of $1 S D$ above and $1 S D$ below mean in Equation 4 yields the graph shown in Figure 1. Results based on Equation 4 led to the conclusion that there was a moderating effect of MNCSIZE. Figure 1 below shows that the 
RCHAR-TCTDEG relationship is stronger (i.e. steeper slope) for medium/small MNCs as compared to large MNCs.

The coefficients table for EXPDEG as shown in Table 4 depicts the results of the regressions equation for Model 1 and Model 2. Model 1 indicates that RCHAR was statistically significant $(p<0.001$; Beta value $=.551)$; and MNCSIZE had only small significant $(p<0.10$; Beta value $=-0.126)$. Equation 5 below shows that for a 1-point increase in RCHAR, the EXPDEG is predicted to have a difference by .109, given that the MNCSIZE is held constant. The regression coefficient associated with MNCSIZE means that the difference in EXPDEG between large and medium/small MNCs is -1.373 , given that RCHAR is held constant.

Equation 5: $\mathrm{EXPDEG}=10.679+.109 \mathrm{RCHAR}-1.373 \mathrm{MNCSIZE}$

Model 2 shows the results after the product term (RCHAR*MNCSIZE) was included in the equation. As indicated in Table 2 the inclusion of product term resulted in an $R^{2}$ change of .010, $[F(1,124)=4.752, p>0.05]$. RCHAR was found statistically significant $(p<0.001$; Beta value $=0.665)$; whereas both MNCSIZE and RCHAR*MNCSIZE were not statistically significant (both at $p>0.05$ ). The results did not show the presence of a significant moderating effect. Table 4 also reveals information on the regression coefficients after the inclusion of product term in the equation. The equation for Model 2 is as follows:

Equation 6: $\mathrm{EXPDEG}=7.182+.132 \mathrm{RCHAR}+4.70 \mathrm{MNCSIZE}-.041 \mathrm{RCHAR} * \mathrm{MNCSIZE}$

The result for Model 2 indicates that for a 1-point increase in the RCHAR, the EXPDEG is predicted to have a difference by .132, given that MNCSIZE is held constant. The interpretation of the regression coefficients for the product term in Equation 6 is that there was a -.041 difference between the slope of EXPDEG on RCHAR between large MNCs and medium/small MNCs. The slope regressing EXPDEG on RCHAR is steeper for medium/small MNCs as compared to large MNCs. The RCHAR and EXPDEG relationship for large and medium/small MNCs is also shown in Figure 1 below. The value of the mean score for RCHAR is 6.68 and for the standard deviation $(S D)$ is 1.23 . The value $1 S D$ above the mean is 7.91 , and the value $1 S D$ below the mean is 5.45. Thus, using the value of $1 S D$ above and $1 S D$ below mean in Equation 6 yields the graph shown in Figure 1. Results based on Equation 6 led to the conclusion that there was no significant moderating effect of MNCSIZE. Although insignificant, Figure 1 below indicates that the RCHAR-EXPDEG relationship is slightly stronger (i.e. steeper slope) for medium/small MNCs as compared to large MNCs.

\section{Discussion and Conclusion}

Building on the underlying KBV and OL perspectives, this study has bridged the literature gaps by providing empirical evidence on the significant moderating effect of size of MNCs on the relationships between relationship characteristics (relationship quality and mutual trust) and two dimensions of degree of technology transfer: degrees of tacit and explicit knowledge using the Malaysia sample. The results suggest that, in comparison, the inclusion of MNCSIZE (large vs. medium/small MNCs) in RCHAR-TCTDEG relationship has a significant moderating effect in changing the degree (volume) of tacit knowledge only $(p<0.001 ; R$ - squared change of 0.073$)$ but not degree of explicit knowledge ( $p>0.05 ; R$ - squared change of 0.010$)$. The moderating effect of MNCSIZE is shown to be capable of changing the nature of relationship and explains under what conditions RCHAR causes TCTDEG. The presence of significant moderating effect of MNCSIZE (large and medium/small MNCs) exceeded the linear relationship between RCHAR and TCTDEG. This is rather interesting given the fact that MNCSIZE has received strong theoretical support in the literature (Hagedoorn and Schakenraad, 1994; Glaister and Buckley, 1996; Hoskisson et al., 1994). The results further suggest that MNCSIZE; whether large or medium/small MNCs, has been established to provide a significant moderating impact in RCHAR-TCTDEG in the JVs. The slopes for TCTDEG on RCHAR for large and medium/small MNCs (Figure 1) indicated that the relationship appeared to be stronger for medium/small MNCs as compared to large MNCs.

The results also provide critical information in such that although transferring tacit knowledge in IJVs requires that the partners to 1) have frequent and effective interactions between partners, openness, spontaneous, and adequacy of communication; which could create potentials for numerous individual exchanges between the JV partners (Szulanski, 1996; Lin, 2005; Inkpen, 2000), and 2) reduce the existence of suspicious feelings between partners in JVs; which could create opportunities for close interactions, increase confidence that both partners would not take advantage on each other, and promote transparency (Kale et al., 2000); nevertheless, due to the nature of knowledge which is highly tacit, complex and firm-specific both large and medium/small MNCs are unlikely to transfer higher degrees of tacit knowledge. Even though medium/small MNCs in JVs are more likely to compromise with local partners in terms of equity ownership to maintain a balanced bargaining power, however, due to their limited resources, expertise and lack of IJVs experience they are most unlikely to undertake technology transfer of tacit knowledge than large MNCs particularly if the transfer involves technologies which form the strategic valuable resources, competencies and source of sustainable competitive advantage of the MNCs (Porter, 1985; Barney, 1991; Peteraf, 1993; Wernerfelt, 1984; Pralahad and Hamel, 1990). 
On the other hand, as compared to medium/small MNCs, although large MNCs are known for having abundant supply of resources, expertise and vast JVs experience to undertake technology transfer, however, due to their inherent advantage, high bargaining power and less dependent on local partners they are also unlikely to transfer a higher degree or technology to local partners. This is also because large MNCs have the propensity to regard their JV as one-way learning processes thus having little to share with local partners (Liu and Vince, 1999; Danis and Park, 2002). Since learning in IJVs is asymmetrical, large MNCs tend to perceive learning as solely the task of the knowledge-disadvantaged local partners (Lin, 2005). The MNCs from the developed countries would normally request for a higher equity ownership in order to increase their bargaining power and have full control of the systems, methods and decisions in the JVs (Makhija and Ganesh, 1997). Large MNCs typically form JVs as the mechanism towards extracting knowledge and information on local business, economics, and political stability (Sinha, 2001). In this sense, in order to maintain their dominance, large MNCs are reluctant to transfer their technologies to local JV partners instead they are more inclining to protect their proprietary technologies and competencies (Taylor, 1995). The results further support and extend the empirical findings by Simonin (1997, 1999a, 2004); where MNCSIZE was found to have moderated the relationships between 1) tacitness and knowledge transfer, and 2) learning intent, learning capacity, knowledge ambiguity and knowledge transfer. The findings also extend technology transfer literature by establishing that MNCSIZE moderates the relationship between RCHAR and degree of tacit knowledge transfer.

One of the major limitations encountered by this study was the resource constraints; where this study has mainly relied on responses obtained from the top management level of the IJVs. Thus, the scope of respondents could have been extended to include the response from middle and lower management levels in the JVs. Secondly, consistent with the literature, the subjectivity of nature of relationship is difficult to capture. Thus, the nature of relationship between IJV partners could have tremendously affected the results if the respondents perceived that the IJVs were competitive in nature rather than collaborative. Thirdly, due to lack of awareness on academic research the response rate in terms of the number of usable questionnaires, though sufficient, was not encouraging. This has become a major challenge to many researchers who conduct organization studies in Malaysia. Finally, due to time constraints, the types of technology under investigation in this study were limited to tacit vs. explicit knowledge dimension.

This empirical study is a response to the need for statistical evidence that has typically been lacking in inter-firm TT literature. Since this study focuses on degree of inter-firm TT, future studies could be conducted to further examine the moderating effects of size of MNCs in the relationships between other technology transfer characteristics such as the recipient, supplier and knowledge characteristics and degree of technology transfer. Secondly, the above relationship could also be extended to cover other formal and externalized inter-firm TT agents such as FDIs and licensing. Thirdly, it is worthwhile to extend the tacit and explicit dimension of technology to cover other dimensions of supply chain activities such as production, marketing, management, and distribution. Fourthly, since the IJV literature has highlighted the high instability rate of IJVs in developing countries, future studies could be directed to empirically examine the moderating effect of size of MNCs on the relationships between degree of inter-firm TT and conflicts, learning outcomes, asymmetric bargaining power, stability of JV, and equity ownership. Finally, future studies could further investigate the effects of few other established moderating variables such as organizational culture, collaborative know-how, prior JV experience, and learning capacity on the above relationships to provide new insights and information on the boundary condition of relationship characteristics-degree of technology transfer relationship.

\section{References}

Aiken, L. S. \& West, S. G. (1991). Multiple Regression: Testing and Interpreting Interacting, Newbury Park, CA: Sage.

Allen, D. R. \& Rao, T. R. (2000). Analysis of Customer Satisfaction Data. United States of America: America Society for Quality.

Aguinis, H. (2004). Regression Analysis for Categorical Moderators, New York, The Gilford Press.

Barney, J.B. (1991). Firm Resources and Sustained Competitive Advantage. Journal of Management, 17, p. 151-166.

Baughn, C. C., Denekamp, J. G, Stevens, J.H. \& Osborn, R.N. (1997). Protecting Intellectual Capital in International Alliances, Journal of World Business, 32(2), p. $103-17$.

Buckley, P.J., Glaister, K.W. \& Husan, R. (2002). International Joint Ventures: Partnering Skills and Cross-Cultural Issues, Long Range Planning, 35(2), p. 113-134.

Bresman, H., Birkinshaw, J. \& Nobel, R. (1999). Knowledge Transfer in International Acquisitions. Journal of International Business Studies, 30(3), p. 439-62.

Cavusgil, S.T., Calantone, R.J. \& Zhao, Y. (2003). Tacit Knowledge Transfer and Firm Innovation Capability. Journal of Business Industrial Marketing, 18(1), p. 6-21. 
Child, J. \& Faulkner, D. (1998). Strategies of Cooperation: Managing Alliances Networks and Joint Ventures. Oxford University, New York.

Choi, C.J. \& Lee, S.H. (1997). A Knowledge-Based View of Cooperative Interorganizational Relationships, In: Beamish P, Killings J, (Eds.). Cooperative Strategies, European Perspectives. San Francisco, CA: New Lexington Press; p. 33-58.

Chua, N. (2002). The Influence of Social Interaction on Knowledge Creation. Journal of Intellectual Capital, 3 (4), p. 375-392.

Clarke, C.M., Robinson, T.M. \& Bailey, J. (1998). Skills and Competence Transfer in European Retail Alliances: A Comparison between Alliances and Joint Ventures. European Business Review, 98 (6), p. 300 -310.

Cohen, J. \& Cohen, P. (1983). Applied Multiple Regression/Correlational Analysis for the Behavioral Sciences $\left(2^{\text {nd }}\right.$ ed. $)$. Hillsdale, NJ: Erlbaum.

Danis, W.M. \& Parkhe, A. (2002). Hungarian-Western Partnership: A Ground Theoretical Model of Integration Processes and Outcomes. Journal of Business Studies, 33(3), p. 423-455.

Davenport, T. H. \& Prusak, L. (1998). Working Knowledge. Boston: Harvard Business School Press.

Davenport, T. H. \& Prusak, L. (2000). Working Knowledge: How Organizations Manage What They Know. Harvard Business School Press, Boston, MA.

Dhanaraj, C., Lyles, M.A., Steensma, H.K. \& Tihanyi, L. (2004). Managing Tacit and Explicit Knowledge Transfer in IJVs: the Role of Relational Embeddedness and the Impact on Performance, Journal of International Business Studies, 35(5), p. 428-42.

Doz, Y. L. \& Hamel, G. (1998). Alliance Advantage. Boston, MA: Harvard Business School Press.

Fryxell, Gerald, E., Robert, D.S. \& Maria, V. (2002). After the Ink Dries: The Interaction of Trust and Control in US-Based International Joint Ventures. Journal of Management Studies, 39, p. 865-887.

Glaister, K.W. \& Buckley, P.J. (1996). Strategic Motives for International Alliance Formation. Journal of Management Studies, 33(3), p. 301-332.

Grosse, R. (1996). International Technology Transfer in Services. Journal of International Business Studies, 27(4), p. 781-800.

Gulati, R. (1995). Does Familiarity Breed Trust? The Implications of Repeated Ties for Contractual Choice in Alliances. Academy of Management Journal 38(1), p. 85-112.

Gupta, A. K. (1987). SBU Strategies, Corporate-SBU Relations, and SBU Effectiveness in Strategy Implementation. Academy of Management Journal, 30, p. 477-500.

Gupta, A. K. \& Govindarajan, V. (2000). Knowledge Flows within Multinational Corporations, Strategic Management Journal, 21(4), p. 473-96.

Hagedoorn, J. \& Schakenraad, J. (1994). The Effect of Strategic Technology Alliances on Company Performance. Strategic Management Journal, 15, p. 291-309.

Hamel G. (1991). Competition for Determinant and Interpartner Learning within International Strategic Alliances. Strategic Management Journal, 12, p. 83-103.

Hau, L. N. \& Evangelista, F. (2007). Acquiring Tacit and Explicit Markrting Knowledge from Foreign Partners in IJVs. Journal of Business Research, 60, pp. 1152-1165.

Hoskisson, R., Johnson, R.A. \& Moesel, D.D. (1994). Corporate Divesture Intensity in Restructuring Firms: Effects of Governance, Strategy, and Performance. Academy of Management Journal, 37, p.1207-1251.

Inkpen, A.C. (2000). Learning through Joint Ventures: A Framework of Knowledge Acquisition. Journal of Management Studies, 37(7), p. 1019-1043.

Inkpen, A. C. (1998a). Learning and Knowledge Acquisition through International Strategic Alliances, The Academy of Management Executive, 12(4), p. 69-80.

Inkpen, A.C. (1998b). Learning and Knowledge Acquisition through International Strategic Alliances. Academy Management Executive, 12(4), p. 69-80.

Inkpen, A.C. \& Beamish, P.W. (1997). Knowledge Bargaining Power and the Instability of International Joint Ventures. Academy of Management Review, 22(1), p. 177-199.

Jaccard, J. J., Turrisi, R., \& Wan, C. K. (1990). Interaction Effects in Multiple Regression. Newbury Park, CA: Sage.

Kale P., Singh H. \& Perlmutter H. (2000). Learning and Protection of Proprietary Assets in Strategic Alliances: Building Relational Capital. Strategic Management Journal, 21(3), p. 217-37.

Khanna, T., Gulati, R. \& Nohria, N. (1998).The Dynamics of Learning Alliances: Competition Cooperation, and Relative Scope, Strategic Management Journal, 19(3), p. 193-210. 
Kogut, B. \& Zander, U. (1993). Knowledge of the Firm and the Evolutionary Theory of the Multinational Corporation. Journal of International Business Studies, 24(4), p. 625-646.

Kogut, B. \& Zander, U. (1992). Knowledge of the Firm, Combinative Capabilities, and the Replication of Technology, Organization Science, 3(3), 383-97.

Kogut, B. (1988). Joint Ventures: Theoretical and Empirical Perspectives, Strategic Management Journal, 9(4), p. 319-32.

Lai, Y. W. \& Narayanan, S. (1997). The Quest for Technological Competence via MNCs: A Malaysian Case Study. Asian Economic Journal, 11 (4), p. 407-422.

Lane, P. J., Salk, J.E. \& Lyles, M.A. (2001). Absorptive Capacity, Learning, and Performance in International Joint Ventures, Strategic Management Journal, 22(12), p. 1139-61.

Lin, X. (2005). Local Partner Acquisition of Managerial Knowledge in International Joint Ventures: Focusing on Foreign Management Control. Management International Review, 45(2), p. 219-237.

Love, P.E.D. \& Gunasekaran, A. (1999). Learning Alliances: A Customer-Supplier Focus for Continuous Improvement in Manufacturing. Industrial and Commercial Training, 31 (3), 88-96.

Liu, S. \& Vince, R. (1999). The Cultural Context of Learning in International Joint Ventures. Journal of Management Development, 18 (8), p. 666-675.

Lyles, M. A. \& Salk, J.E. (1996). Knowledge Acquisition from Foreign Parents in International Joint Ventures: An Empirical Examination in the Hungarian. Journal of International Business Studies, 29(2), p. 154-74.

Makhija, M.V. \& Ganesh, U. (1997). The Relationship between Control and Partner Learning-Related Joint Ventures. Organization Science, 8(5), p. 508-527.

Marcotte, C. \& Niossi, J. (2000). Technology Transfer to China: The Issues of Knowledge and Learning, Journal of Technology Transfer, 25, p. 43-57.

Marquardt, M. \& Reynolds, A. (1994). Global Learning Organizations. New York: Irwin

Minbaeva, D. (2007). Knowledge Transfer in Multinationals, Management International Review, 47(4), p. 567-593.

Mohamed, M.Z. (1998). Assessing the Competitiveness of the Malaysian Electronic and Electrical Industry: Part 1-Technology Adoption. Malaysian Management Review, 33(10), p. 19-20.

Mohr, J.J. \& Sengupta, S. (2002). Managing the Paradox of Interfirm Learning: The Role of Governance Mechanisms. Journal of Business Industrial Marketing; 17(4), p. 282-301.

Morrison, M. \& Mezentseff, L. (1997). Learning Alliances - A New Dimension of Strategic Alliances. Management Decision, MCB University Press, 35(5), p. 351-357.

Mowery, D.C., Oxley J.E. \& Silverman B.S. (1996). Strategic Alliances and Interfirm Knowledge Transfer. Strategic Management Journal, 17, p. 77-91.

Narayanan, S. \& Lai, Y. W. (2000). Technological Maturity and Development without Research: The Challenge for Malaysian Manufacturing. Development and Change, 31, p. 435-457.

Newman, L. W. (2003). Social Research Methods: Qualitative and Quantitative Approaches. (5 ${ }^{\text {th }}$ Eds). Allyn and Bacon. Boston. MA.

Nonaka, I. (1994). A Dynamic Theory of Organizational Knowledge Creation. Organization Science, 5, p. $14-37$.

Pak, Y. \& Park, Y. (2004). A Framework of Knowledge Transfer in Cross-Border Joint Ventures: An Empirical Test of the Korean Context, Management International Review, 44(4), p. 435-455.

Petaraf, M.A. (1993). The Cornerstone of Competitive Advantage: A Resourced-Based View. Strategic Management Journal, 14(3), p. 179-192.

Porter, M.E. (1980). Competitive Strategy. Free Press, New York.

Porter, M.E. (1985). Competitive Advantage: Creating and Sustaining Superior Performance. Free Press: New York.

Pralahad, C.K. \& Hamel, G. (1990). The Core Competence of the Corporation. Harvard Business Review, 68, p. 77-91.

Sekaran, U. (2003). Research Methods for Business, Fourth Edition, John Wiley \& Sons, Inc.

Simonin, B. L. (2004). An Empirical Investigation of the Process of Knowledge Transfer in International Strategic Alliances, Journal of International Business Studies, 35(5), 407-27.

Simonin, B. L. (1999a). Ambiguity and the Process of Knowledge Transfer in Strategic Alliances, Strategic Management Journal, 20(7), p. 595-623. 
Simonin, B.L. (1999b). Transfer of Marketing Know-how in International Strategic Alliances: An Empirical Investigation of the Role and Antecedents of Knowledge Ambiguity. Journal of International Business Studies, 30(3) p. 463-90 [Third Quarter].

Sinha, U.B. (2001). International Joint Venture, Licensing and Buy-out under Asymmetric Information. Journal of Development Economics, 66(1), p. 127-151.

Smith, K.G., Carroll, S.J. \& Ashford, S.J. (1995). Intra and Inter OrganizationaC: Towards a Research Agenda. Academy of Management Journal, 38(1), p.7-23.

Steensma, H. K. \& Lyles, M.A. (2000). Explaining IJV Survival in a Transitional Economy through Social Exchange and Knowledge-based perspectives, Strategic Management Journal, 21(8), p. 831-51.

Szulanski, G. (2003). Sticky Knowledge: Barriers to Knowing in the Firm, London: SAGE Publications.

Szulanski, G. (2000). Appropriability and the Challenge of Scope: Bank One Routinizes Replication, in Dosi, G.

Nelson, R. Winter, S. (Eds.), the Nature and Dynamics of Organizational Capabilities, New York: Oxford University Press.

Szulanski, G. (1996). Exploring Internal Stickiness: Impediments to the Transfer of Best Practice within the Firm, Strategic Management Journal, 17 (Winter Special Issue), p. 27-43.

Taylor, M.Z. (1995). Dominance Through Technology: Is Japan Creating a Yen Block in Southeast Asia? Foreign Affairs, 74 (6), p.14-20.

Tsang E.W.K., Tri D.N. \& Erramilli M.K. (2004). Knowledge Acquisition and Performance of International Joint Ventures in the Transition Economy of Vietnam. Journal of International Marketing, 12(2), p. 82-103.

Uzzi, B. (1997). Social Structure and Competition in Interfirm Networks: The Paradox of embeddedness. Administrative Science Quarterly, 42, p. 35-67.

Wang, Y. \& Nicholas, S. (2005). Knowledge Transfer Replication, and Learning in Non-Equity Alliance: Operating Contractual Joint Ventures in China. Management International Review, 45(1), p. 99-118.

Wang, P., Tong, T.W. \& Koh, C.P. (2004). An Integrated Model of Knowledge Transfer from MNC Parent to China Subsidiary. Journal of World Business, 3I (2), p. 168-182.

Wathne, K., Roos, J. \& von Krogh, G. (1996). Towards a Theory of Knowledge Transfer in a Cooperative Context, in: von Krogh, G. and Roos, J. (Eds.), Managing Knowledge Perspectives on Cooperation and Competition, Sage Publications: London, 51-81.

Wernerfelt, B. (1984). A Resource-Based View of the Firm, Strategic Management Journal, 5(2), p. 171 - 80.

Yin, E. \& Bao, Y. (2006). The Acquisition of Tacit Knowledge in China: An Empirical Analysis of the 'Supplier-side Individual Level' and 'Recipient-side' Factors. Management International Review, 46(3), p. 327-348.

Zander, U. \& Kogut, B. (1995). Knowledge and the Speed of the Transfer and Imitation of Organizational Capabilities: An Empirical Test. Organization Science, 6(1), p. 76-92.

Table 1. Model Summary ${ }^{c}$ - Degree of Tacit Knowledge

\begin{tabular}{|c|c|c|c|c|c|c|c|c|c|}
\hline \multicolumn{10}{|c|}{ Model Summaryc } \\
\hline \multirow[b]{2}{*}{ Model } & \multirow[b]{2}{*}{$\mathrm{R}$} & \multirow[b]{2}{*}{ R Square } & \multirow[b]{2}{*}{$\begin{array}{l}\text { Adjusted } \\
\text { R Square }\end{array}$} & \multirow[b]{2}{*}{$\begin{array}{l}\text { Std. Error of } \\
\text { the Estimate }\end{array}$} & \multicolumn{5}{|c|}{ Change Statistics } \\
\hline & & & & & $\begin{array}{l}\text { R Square } \\
\text { Change }\end{array}$ & F Change & df1 & df2 & Sig. F Change \\
\hline 1 & $.543^{a}$ & .295 & .284 & 4.912 & .295 & 26.126 & 2 & 125 & .000 \\
\hline 2 & $.607^{\mathrm{b}}$ & .368 & .353 & 4.670 & .073 & 14.334 & 1 & 124 & .000 \\
\hline
\end{tabular}


Table 2. Model Summary ${ }^{c}$ - Degree of Explicit Knowledge

Model Summaryc

\begin{tabular}{|c|c|c|c|c|c|c|c|c|c|}
\hline \multirow[b]{2}{*}{ Model } & \multirow[b]{2}{*}{$\mathrm{R}$} & \multirow[b]{2}{*}{ R Square } & \multirow[b]{2}{*}{$\begin{array}{l}\text { Adjusted } \\
\text { R Square }\end{array}$} & \multirow[b]{2}{*}{$\begin{array}{l}\text { Std. Error of } \\
\text { the Estimate }\end{array}$} & \multicolumn{5}{|c|}{ Change Statistics } \\
\hline & & & & & $\begin{array}{l}\text { R Square } \\
\text { Change }\end{array}$ & F Change & df1 & $\mathrm{df} 2$ & Sig. F Change \\
\hline 1 & $.594^{\mathrm{a}}$ & .353 & .342 & 4.364 & .353 & 34.032 & 2 & 125 & .000 \\
\hline 2 & $.602^{\mathrm{b}}$ & .362 & .347 & 4.348 & .010 & 1.921 & 1 & 124 & 168 \\
\hline
\end{tabular}
a. Predictors: (Constant), MNCSIZE, RCHAR
b. Predictors: (Constant), MNCSIZE, RCHAR, RCHAR*MNCSIZE
c. Dependent Variable: EXPDEG

Table 3. Coefficients ${ }^{\mathrm{a}}$ - Degree of Tacit Knowledge

Coefficients $^{\mathrm{a}}$

\begin{tabular}{|c|c|c|c|c|c|c|c|c|}
\hline \multirow[b]{2}{*}{ Mod } & & \multicolumn{2}{|c|}{$\begin{array}{c}\text { Unstandardized } \\
\text { Coefficients }\end{array}$} & \multirow{2}{*}{$\begin{array}{c}\text { Standardized } \\
\text { Coefficients }\end{array}$} & \multirow[b]{2}{*}{$t$} & \multirow[b]{2}{*}{ Sig. } & \multicolumn{2}{|c|}{$95 \%$ Confidence Interval for B } \\
\hline & & B & Std. Error & & & & Lower Bound & Upper Bound \\
\hline & (Constant) & 10.979 & 2.646 & & 4.149 & .000 & 5.742 & 16.216 \\
\hline & RCHAR & .096 & .017 & .451 & 5.829 & .000 & .064 & .129 \\
\hline & MNCSIZE & -2.520 & .910 & -.214 & -2.769 & .006 & -4.321 & -.719 \\
\hline \multirow[t]{4}{*}{2} & (Constant) & .719 & 3.697 & & .195 & .846 & -6.599 & 8.038 \\
\hline & RCHAR & 163 & .024 & .761 & 6.913 & .000 & 116 & 209 \\
\hline & MNCSIZE & 15.297 & 4.785 & 1.300 & 3.197 & .002 & 5.827 & 24.768 \\
\hline & RCHAR*MNCSIZE & -.120 & .032 & -1.496 & -3.786 & .000 & -.182 & -.057 \\
\hline
\end{tabular}

a. Dependent Variable: TCTDEG

Table 4. Coefficients ${ }^{\mathrm{a}}$ - Degree of Explicit Knowledge

Coefficients $^{\text {a }}$

\begin{tabular}{|c|c|c|c|c|c|c|c|c|}
\hline \multirow{2}{*}{\multicolumn{2}{|c|}{ Model }} & \multicolumn{2}{|c|}{$\begin{array}{l}\text { Unstandardized } \\
\text { Coefficients }\end{array}$} & \multirow{2}{*}{$\begin{array}{c}\begin{array}{c}\text { Standardized } \\
\text { Coefficients }\end{array} \\
\text { Beta }\end{array}$} & \multirow[b]{2}{*}{$\mathrm{t}$} & \multirow[b]{2}{*}{ Sig. } & \multicolumn{2}{|c|}{$95 \%$ Confidence Interval for B } \\
\hline & & $\mathrm{B}$ & Std. Error & & & & Lower Bound & Upper Bound \\
\hline & (Constant) & 10.679 & 2.351 & & 4.543 & .000 & 6.027 & 15.331 \\
\hline & RCHAR & 109 & .015 & .551 & 7.439 & .000 & .080 & .138 \\
\hline & MNCSIZE & -1.373 & .808 & -.126 & -1.698 & .092 & -2.973 & .227 \\
\hline \multirow[t]{4}{*}{2} & (Constant) & 7.182 & 3.442 & & 2.086 & .039 & .369 & 13.996 \\
\hline & RCHAR & .132 & .022 & .665 & 6.018 & .000 & .088 & .175 \\
\hline & MNCSIZE & 4.700 & 4.455 & .431 & 1.055 & .293 & -4.118 & 13.517 \\
\hline & RCHAR*MNCSIZE & -.041 & .029 & -.550 & -1.386 & .168 & -.099 & .017 \\
\hline
\end{tabular}

a. Dependent Variable: EXPDEG 


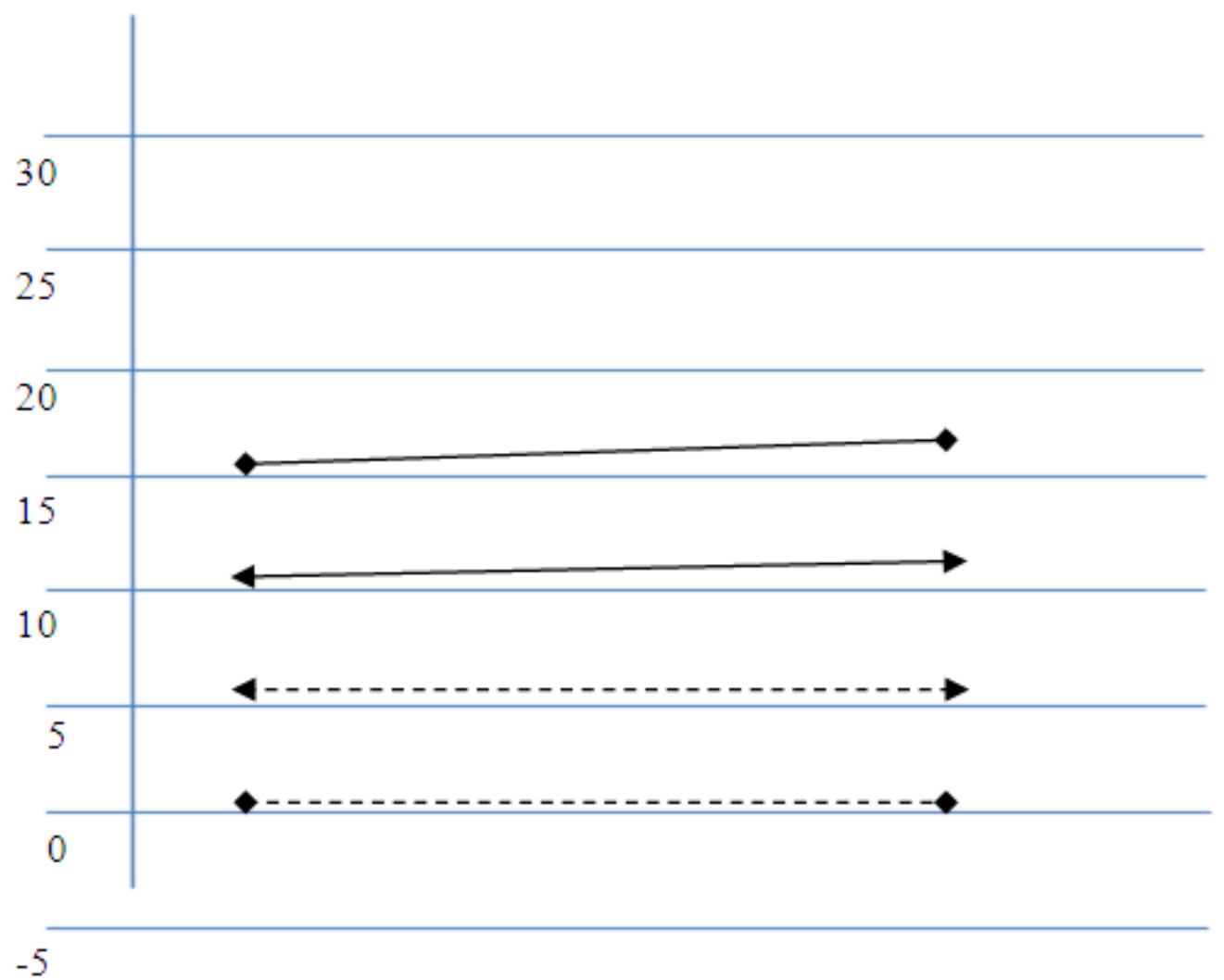

Figure 1. Slopes for both TCTDEG and EXPDEG on RCHAR for MNCSIZE

Low TCTDEG / EXPDEG (1 SD below mean)

High TCTDEG / EXPDEG (1 SD above mean)

- medium and small MNCs (TC TDEG)

$\bullet$ large MNCs (TCTDEG)

$\rightarrow$ medium and small MNCs (EXPDEG)

$4--\rightarrow$ large $\mathrm{MNCs}$ (EXPDEG) 